\title{
The Contribution of the Geospatial Information to the Hydrological Modelling of a Watershed with Reservoirs: Case of Low Oum Er Rbiaa Basin (Morocco)
}

\author{
Youness Kharchaf, Hassan Rhinane, Abdelhadi Kaoukaya, Abdelhamid Fadil \\ Geosciences Laboratory, Faculty of Sciences-Ain Chock, Hassan II University, Casablanca, Morocco \\ Email: khirchoff2001@gmail.com,h.rhinane@gmail.com, a.kaoukaya@fsac.ac.ma, a_fadil@yahoo.com
}

Received March 12, 2013; revised April 12, 2013; accepted May 12, 2013

Copyright (C) 2013 Youness Kharchaf et al. This is an open access article distributed under the Creative Commons Attribution License, which permits unrestricted use, distribution, and reproduction in any medium, provided the original work is properly cited.

\begin{abstract}
Water is undoubtedly the most vital natural resource. Water use management is one of the greatest challenges that face humanity. The demand for water is continuously growing because of the population growth, the intensive urbanization and the development of industrial and agricultural activities. To face the increasing pressure on this vital resource, it is so necessary to set up the adequate instruments to ensure a rational and efficient management of this resource. In this context, the hydrological modeling is largely used as an instrument to assess the functioning of these resources at watershed scale. In addition, the use of spatial models let to depict and simulate the watershed processes at small spatial and heterogeneous scales that reflect the field reality more accurate and more realistic as possible. However, the use of spatial models requires geospatial data that must be gathered at very fine scales. The aim of this study is to highlight the contribution of geospatial data to assess the hydrologic modeling of watershed by using a spatial hydro-agricultural model, notably the SWAT model (Soil and water Assessment Tool). The study area is the Basin of Low Oum Er Rbiaa River which extends from the Al Massira dam to its outlet in the Atlantic Ocean. This watershed includes a set of dams (Daourat, Imfout and Sidi Mâachou) built in waterfall fashion along the river. The objective was to simulate the hydrological functioning of this area that had never been modeled in order to assess the management of these reservoirs used essentially to produce electricity and fresh water. The implementation of the SWAT model required a spatial database that was built from topography, soil, land use and climate data. The calibration and validation of the model was carried out on a daily basis over several years (2001-2010) using The ArcSWAT tool integrated in ArcGIS software and the Parasol optimization method. The calibration of SWAT model was successfully done with 0.6 as value of Nash coefficient used commonly in hydrology to evaluate the model performance. The calibrated model was then used to estimate the hydrological balance sheet of the Low Oum Er Rbiaa to model the intermediate contribution of the three reservoirs situated in the watershed.
\end{abstract}

Keywords: Modeling; Hydrology; Low Oum Er Rbiaa; Reservoirs; GIS; SWAT; ArcSWAT; Watershed

\section{Introduction}

Water is a fundamental substance for life preservation. It is also a factor of a great utility in agriculture, energy production, industry, domestic use and in other daily life activities [1]. Taking into account the increasing necessity of the human needs in water, several actions were taken in the Moroccan context to deal with the problems related to water.

To face all these problems, it is essential to set up the adequate instruments for the management, the follow-up and the planning of this vital resource. In this respect, the hydrological modeling is an essential element which al- lows a better understanding of the hydrological functioning of the studied watershed and the study of the various challenges to which a watershed is exposed: floods, drought, erosion, pollution, climate change, etc. Using a distributed approach based on spatial data is a major asset for the process of watershed modeling since it allows representing and simulating the different components of the model inputs and an accurate and more realistic spatial scale. The use of spatial model is made possible by the spatial information acquisition and the processing techniques, especially remote sensing and GIS. In fact, the global models dealing with watersheds as a single entity are generally contested in their ability 
to represent the reality of space that is characterized by its complexity, heterogeneity and uniformity.

Hydrological modeling is based on the presentation in mathematical equations of the main components of the water cycle, taking into account the physical and geomorphological characteristics of the study area [2]. The objectives of modeling are multiple: understanding (the functioning of the watershed, the hydrological balance sheet), forecast (floods, drought, management of the irrigation) and simulation of scenarios (climate change, effects of the anthropological arrangements developments) [3].

The presence of natural reservoirs (lakes) or anthropogenic (dams) in the studied area must be taken into account because of the role they play in the flow of water. These reservoirs further complicate the implementation process of the conceptualization of the functioning of watersheds in that all the information concerning the methods of management and operation of these reservoirs: Inputs, outputs, sampling, discharges etc. should be available.

Many hydrological models have been developed and tested worldwide, yet lack of data remains the main obstacle hindering the deployment and widespread use of these models [4]. The emergence of new technologies, acquisition and processing of spatial information notably the GIS and remote sensing constitute a solution and highly promising opportunity that can overcome some of these barriers by offering new solutions and alternatives for the acquisition and the management of the data particularly on a more interesting spatial scale [5].

In this context, the objective of this study is to propose an approach based on the use of spatial data to simulate the behavior of the watershed low Oum Er Rbiaa, taking into account the existence of the three dams which constitute basin waterfalls. The advantage of this approach lies in having a good spatialized hydrological account of the basin knowing that it has never been modeled due to the lack of gauging stations in the studied area.

The model used is the agro-hydrological model SWAT (Soil and Water Assessment Tool), developed in 1999 by Jeff Arnold for the "USDA-Agriculture Research Service" [6].

\section{Materials and Methods}

\subsection{Description of the Study Area}

The basin of the Oum-Er Rbiaa (Figure 1) extends over an area of $34,000 \mathrm{~km}^{2}$, taking the name of one of the largest rivers in the country "Oued Oum Er Rbiaa" with a length of $555 \mathrm{~km}$, located West between longitudes $5^{\circ} 04^{\prime}$ and $8^{\circ} 20^{\prime}$ north latitude and $31^{\circ} 20^{\prime}$ and $33^{\circ} 12^{\prime}$. The source of this river is in the north-western High Atlas limestone, and in the Middle Atlas. It runs across the plain of Tadla and plateau of Phosphates, before skirting the plain of Doukkala. The outlet of this river is in the

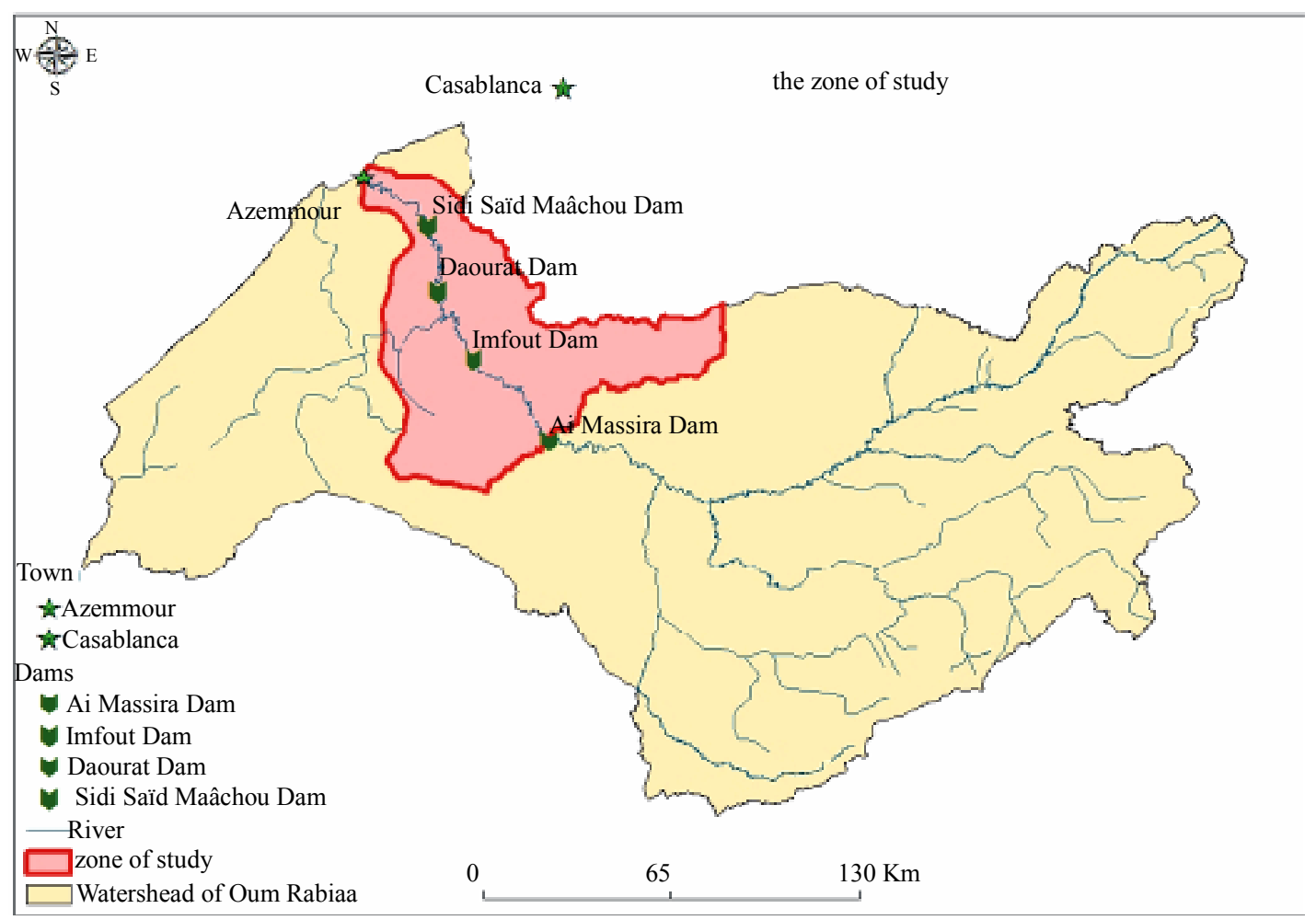

Figure 1. Map of the zone studied. 
Atlantic Ocean in the coastal town of Azemmour [7].

This basin is considered a hydraulic reservoir for the country and a set of eight dams have been built on it. Our study concerns specifically the lower area of the Oum Er Rbiaa basin from Al Massira dam to the Atlantic Ocean. This area has three dams Imfout (built in 1944), Daourat (built in 1950), Sidi Maachou (built in 1929). The purpose of these dams is the production of electricity as well as:

- Irrigation of Doukkala and providing drinking water and irrigation for Safi (Imfout dam);

- Providing drinking water and irrigation for Casablanca and Settat (Daourat dam);

- Providing drinking water and irrigation for Casablanca and El Jadida (Sidi Mâachou dam).

The climate of the Oum Er Rbiaa basin is very diverse, ranging from humidity and sub humidity in the mountains to semi-aridity to aridity in the middle and lower parts of the basin. The average rainfall in the Basin is $520 \mathrm{~mm}$ with a high spatial and seasonal variation [8].

\subsection{Description of the SWAT Model}

The Soil and Water Assessment Tool (SWAT) is an agro-hydrological watershed scale model developed by Agricultural Research Services of the USDA. It is a physically based and semi-distributed model that operates on continuous time basis [9].

SWAT allows simulating the major watershed processes as hydrology, sedimentation, nutrients transfer, crop growth, environment and climate change. The aim is to depict the physical functioning of these different components and their interactions as simply and realistically as possible through conceptual equations and the use of available input data so as to make it useful in routine planning and decision making of large catchments management [10].

One of the main goals of SWAT model is to predict the impact of land management practices on water quantity and quality over long periods of time for large complex watersheds that have varying soils, land use and management practices [11]. The model generates a spatial water balance. It controls the various hydrological processes occurring in the basin.

In fact, the SWAT model was used in Indiana for instance to model the movements of pesticides in a basin of $250 \mathrm{~km}^{2}$. It is used in Germany in the basin Dietzhöle. It has also been adopted in West Africa in the modeling of soil degradation, especially by making scenarios on the impact of climate change and land use [12-14].

\subsection{Hydrological Compartments of the Model SWAT}

The hydrological shutter is simulated by the model
SWAT according to the following Equation (1) [11]:

$$
S W_{t}=S W_{0}+\sum_{i=1}^{t}\left(R_{\text {day }}-Q_{\text {surf }}-E_{a}-W_{\text {seep }}-Q_{g w}\right)_{i}
$$

$S W_{t}=$ soil water content $(\mathrm{mm})$

$S W_{0}=$ water available to plants $(\mathrm{mm})$

$R_{\text {day }}=$ precipitation $(\mathrm{mm})$

$Q_{\text {surf }}=$ surface $\operatorname{runoff}(\mathrm{mm})$.

$E_{a}=$ evapotranspiration (mm)

$W_{\text {seep }}=$ percolation $(\mathrm{mm})$

$Q_{g w}=$ low flow (mm)

$t=$ time (days)

The Figure 2 shows the general sequence of processes used by SWAT to model the land phase of the hydrologic cycle [11].

\subsection{Creation of the Database}

The Implementation of the SWAT model requires the creation of a database containing morphological description (topography), physical description (pedology and land use) and climate (precipitation, temperature, etc.) of the basin. These layers of information must also be associated with a set of attributes describing the properties of each layer.

The representation of these data must be spatial with the highest possible resolution and the one most adapted to the studied area.

Thus, the preparation of the spatial database required a series of tasks carried out primarily through ArcGIS and Erdas Imagine tools and which can be summarized as follows:

- The recovery of digital model representing the relief of the studied area;

- The digitalization of the soil and geological map of the studied area;

- The processing of satellite images through the process of supervised classification for extracting land use map;

- Recovery and structuring in adequate files of data on the climate at the meteorological stations studied;

- The processing of these climate files in order to determine the missing data and complete these files using statistical procedures;

- Collecting and structuring data concerning the inputs and outputs of the three reservoirs: Imfout, Daourat and Sidi Maachou.

All these data have been created or projected to the coordinate system used in this project which is the Lambert Conformal Conic zone one of Morocco.

All these tasks are depicted in Figure 3 below.

The main sets of data used are briefly explained below:

\section{- Pedology}

Digitizing the soil map was produced from the soil 


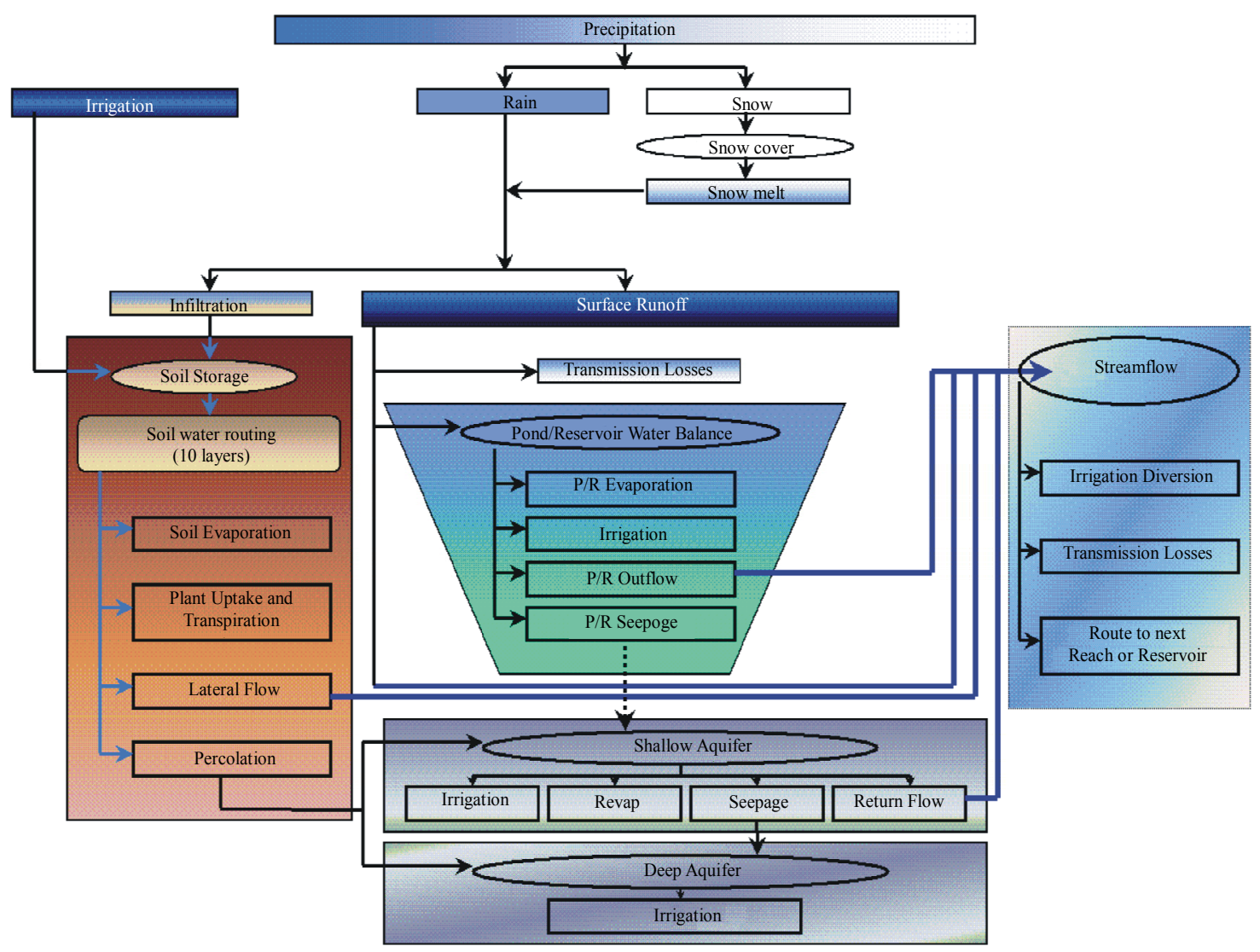

Figure 2. Schematic of pathway available for water movement in SWAT.

- DEM
- Land use
- Soil
- Location o: Weather Sta-ions
- Weather Time series

Figure 3. Components and input/output data of SWAT model. 
map of central Morocco set by the department of the physical environment of the National Institute of Agronomic Research on the scale of 1:500,000 published in 2001. The area consists of several types of soil. the proportion of the area is marked by the dominance of "Calcimagnesian" soil (25\%), "Isohumic" soil (17\%), the "Mineral Brutes" soil and the "littlel Evolved" soils which are respectively $14 \%$ and $13 \%$ of the total surface area (Figure 4(a)).

\section{- Land Use}

The land use map (Figure 4(b)) was developed from a combination of data sources including:

- The satellite image processing LANDSAT4 through directed classification;

- The data collected and recovered from various agencies: hydraulics agency, agriculture department etc.;

- The type of land use is dominated by the culture Bour which covers $80 \%$ of the basin and that spans the entire basin, while the distance covered does not exceed $7 \%$ as irrigated crops occupy $5 \%$, and the bare soil $4 \%$ of the entire basin. Forest areas are also poorly implemented and only $2 \%$ of the total area of the basin.

\section{- Geology}

The geological map (Figure 4(c)) was obtained through the digitization of a set of geological maps (1:250,000) of Morocco. The analysis of this map highlighted certain characteristics of the zone of study as the nature of aquifers and the permeability.

\section{- Digital Terrain Model (DTM)}

Digital Terrain Model (Figure 4(d)) is extracted from the ASTER GDEM satellite with a spatial resolution of $30 \mathrm{~m}$. The DTM is one of the most important data used to run the SWAT model.

\section{Climate and Hydrometry}

The study area contains no hydrometric station, no stations of measuring precipitation or temperature. The main station used to this end is located at the dam Al Massira which is managed by the Hydraulic Basin Agency of Oum Er Rbiaa. In addition to this station the Nouasseur station located near the basin was used for the integration of climate information.

For the three reservoirs managed by the National Office of Electricity, the available measures are just the monthly hydric balance sheets of the studied period. These data include the contributions of rivers, outputs, turbined volumes and samples.

The structuring of a series of climate data on a daily scale required some statistical treatments. Indeed, the analysis of temperature data shows some data missing at

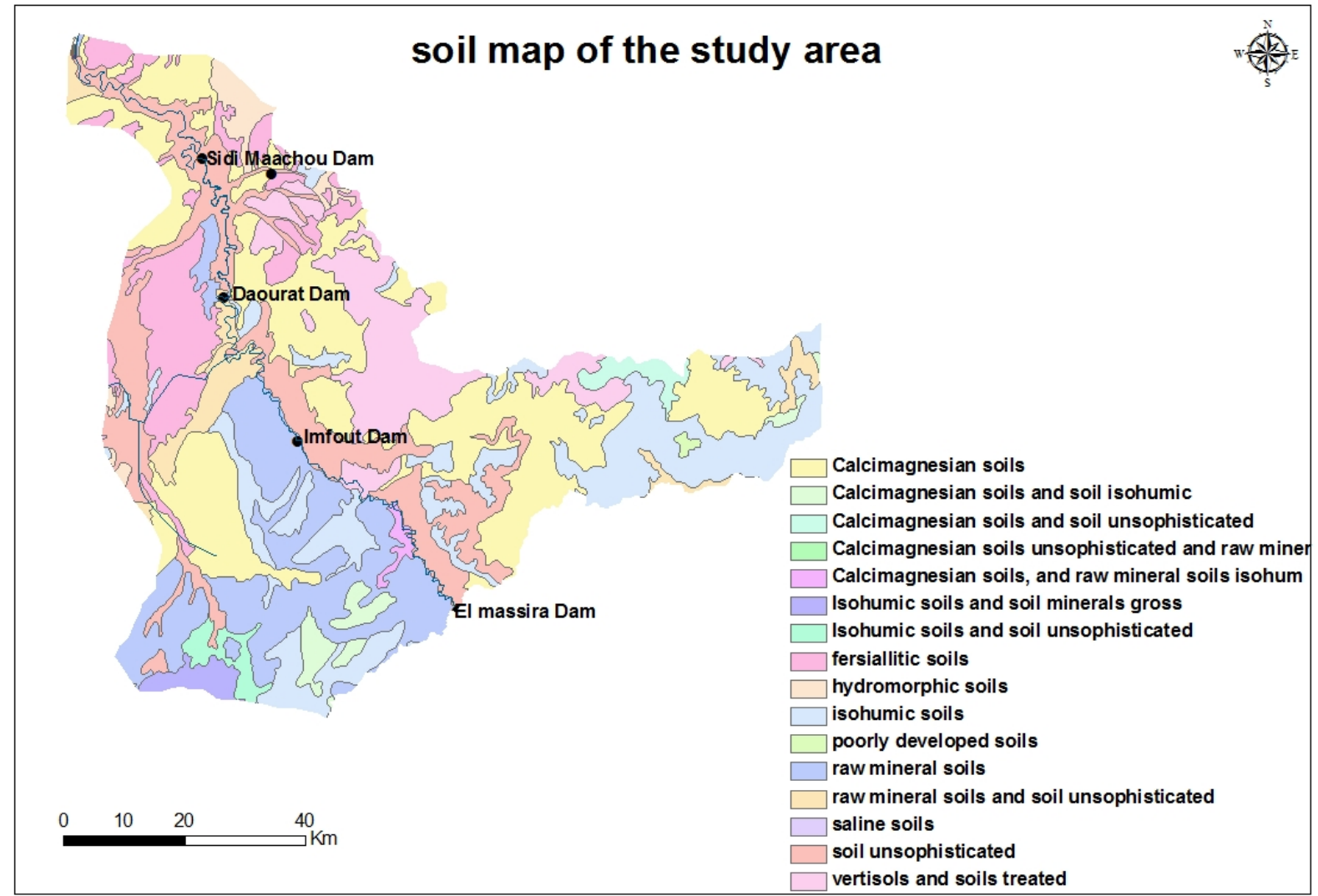

(a) 


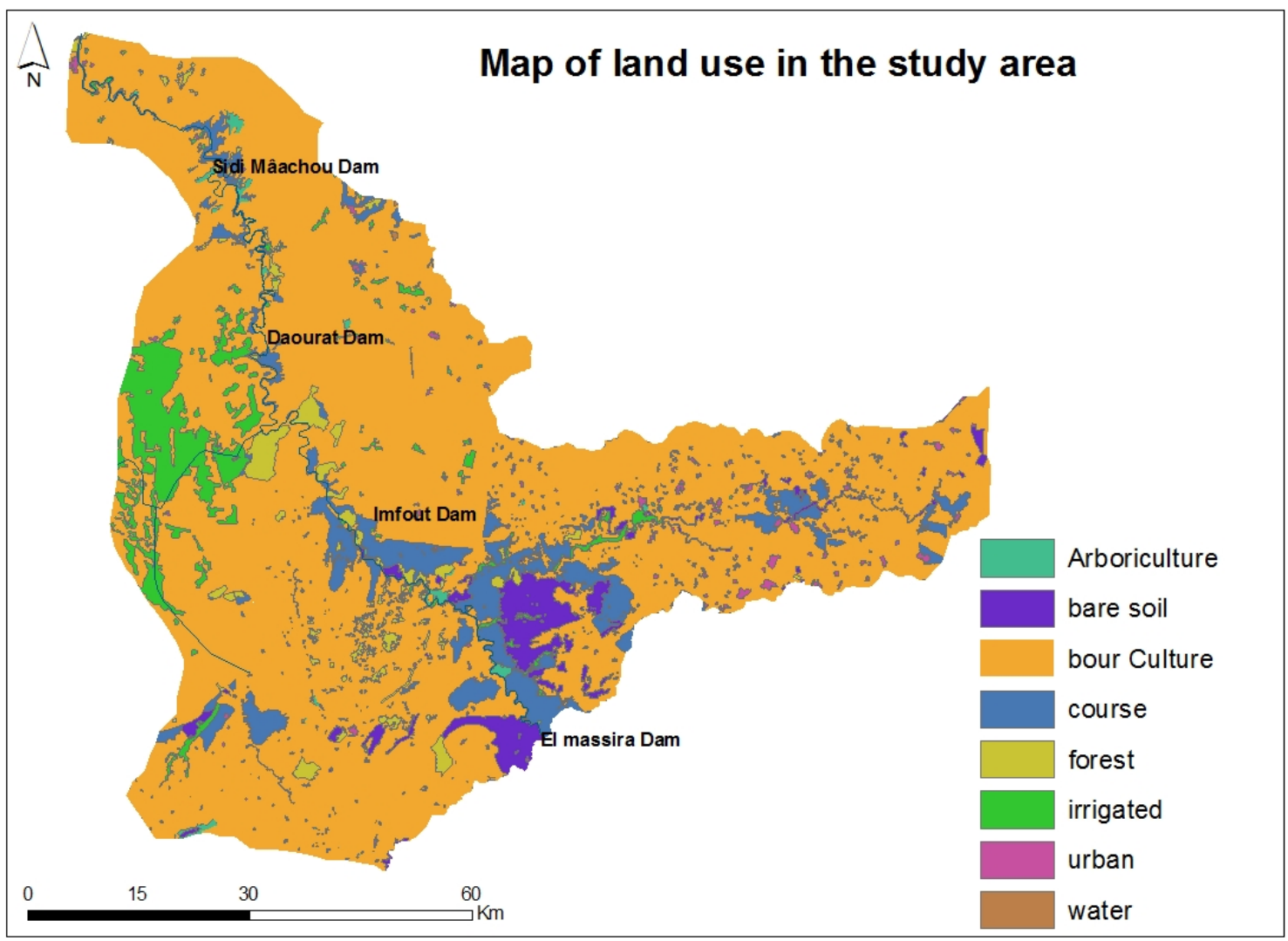

(b)

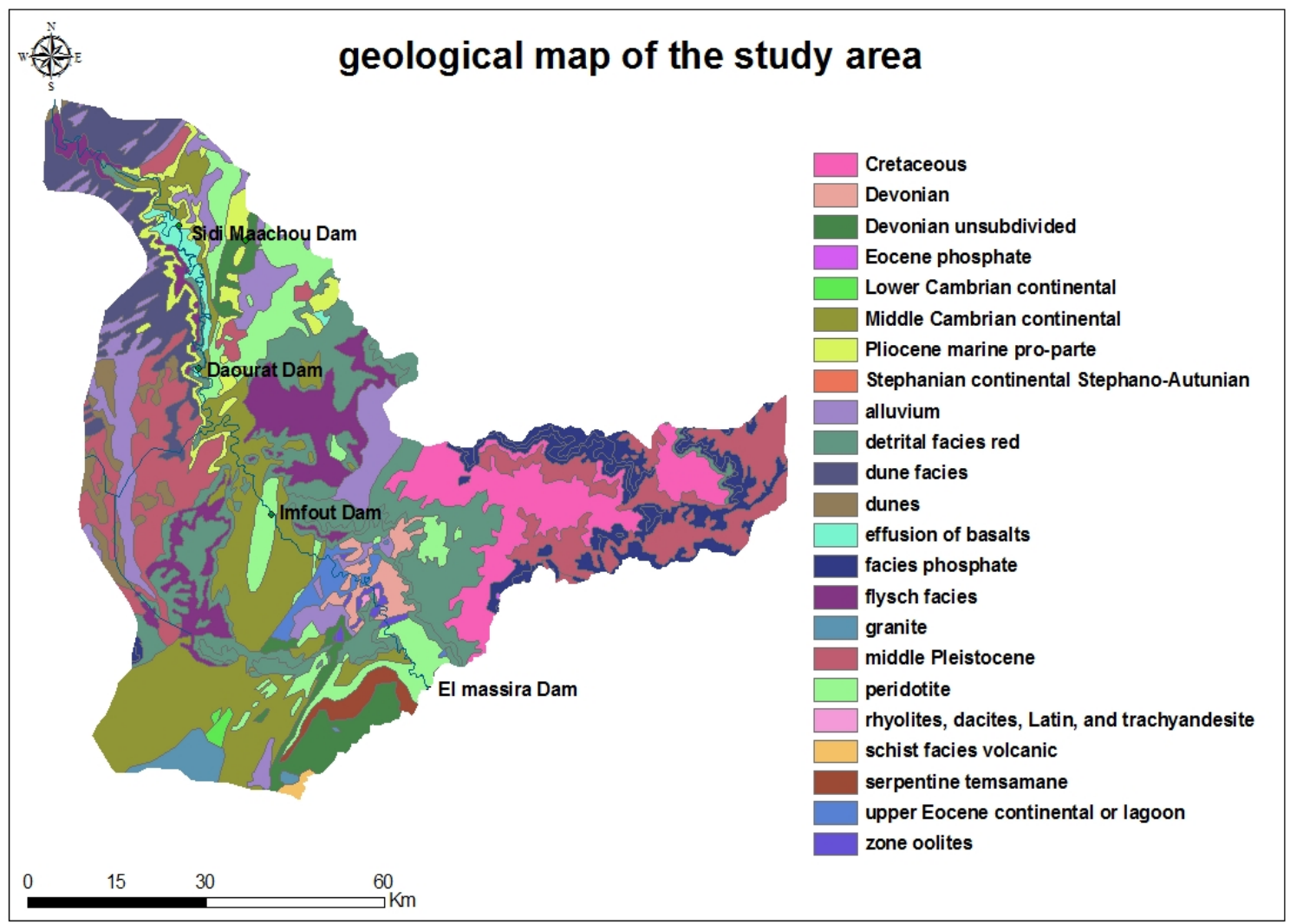

(c) 


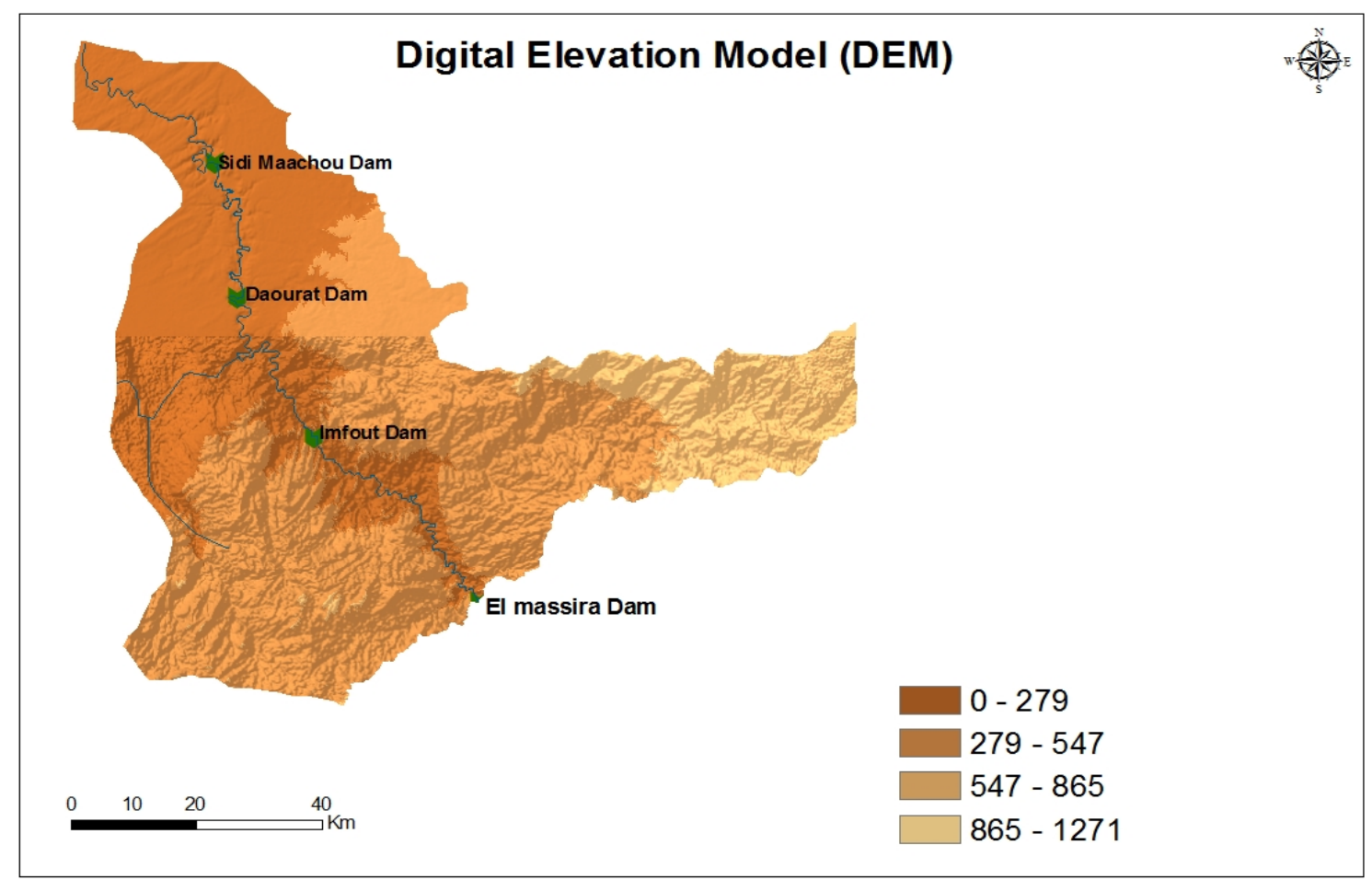

(d)

Figure 4. (a) Soil map; (b) Map of land use; (c) Geological map; (d) Digital elevation model (DEM).

some daily observations. A procedure has been developed to address these missing data by adopting this approach focusing on the following two axes:

- When the number of missing values is less than 4 , the missing values are replaced by the average of the observations around.

- When the number of missing values is upper or equals 4 , the missing values are replaced by the attested averages for the same periods in similar years for which information is available.

\subsection{Configuration Model}

After preparing all the data required by the SWAT model, the next step in the modeling process for the Lower Oum Er Rbiaa Basin was to set up the model. Thus, the intersection of temporal data available on climate has led us to choose the period 2001-2010 for the implementation of the model. The configuration of SWAT was made along the following parameters:

- Time input scale: daily

- Time output scale: monthly

- Application period: 10 years (2001-2010)

- Initialization of the model: one year (2001)

- Calibration of the model: 4 years (2002-2005)

- Model Validation: 5 years (2006-2010)

Application of SWAT model requires a number of steps in order to arrive at the desired result. These are mainly the following steps:

- The introduction of DEM in the model;

- The introduction of the outlet of the study area;

- The generation of drainage;

- Specifying the location of reservoirs, dams in our case;

- The division of the basin into sub-basins, indicating to the model the points to consider as exit points (outfalls secondary sub-basin) and which must include the reservoirs mentioned above. This step helped generate 28 sub-basins constituting the backbone of the study area (Figure 5);

- The introduction of layers of soil and land use by filling the necessary attributes.

Following this implementation, the model generates, through the intersection of the DEM, soil, land use and sub-basins, the spatial units of work called "HRU" and which represent a hydrologic response. Each of these units consists of the same class of slope, soil and land use [15]. These units represent the spatial resolution and basic operation of the SWAT model. All processes modeled by SWAT are simulated at the spatial scale of these units.

To avoid generating very small units and a very large number units by combining the four layers mentioned above, a tolerance of $10 \%$ was introduced in the model to avoid entities of slope, soil or land use that occupy less than $10 \%$ of the surface of the sub-basins while also excluding through this procedure the most sensitive types 


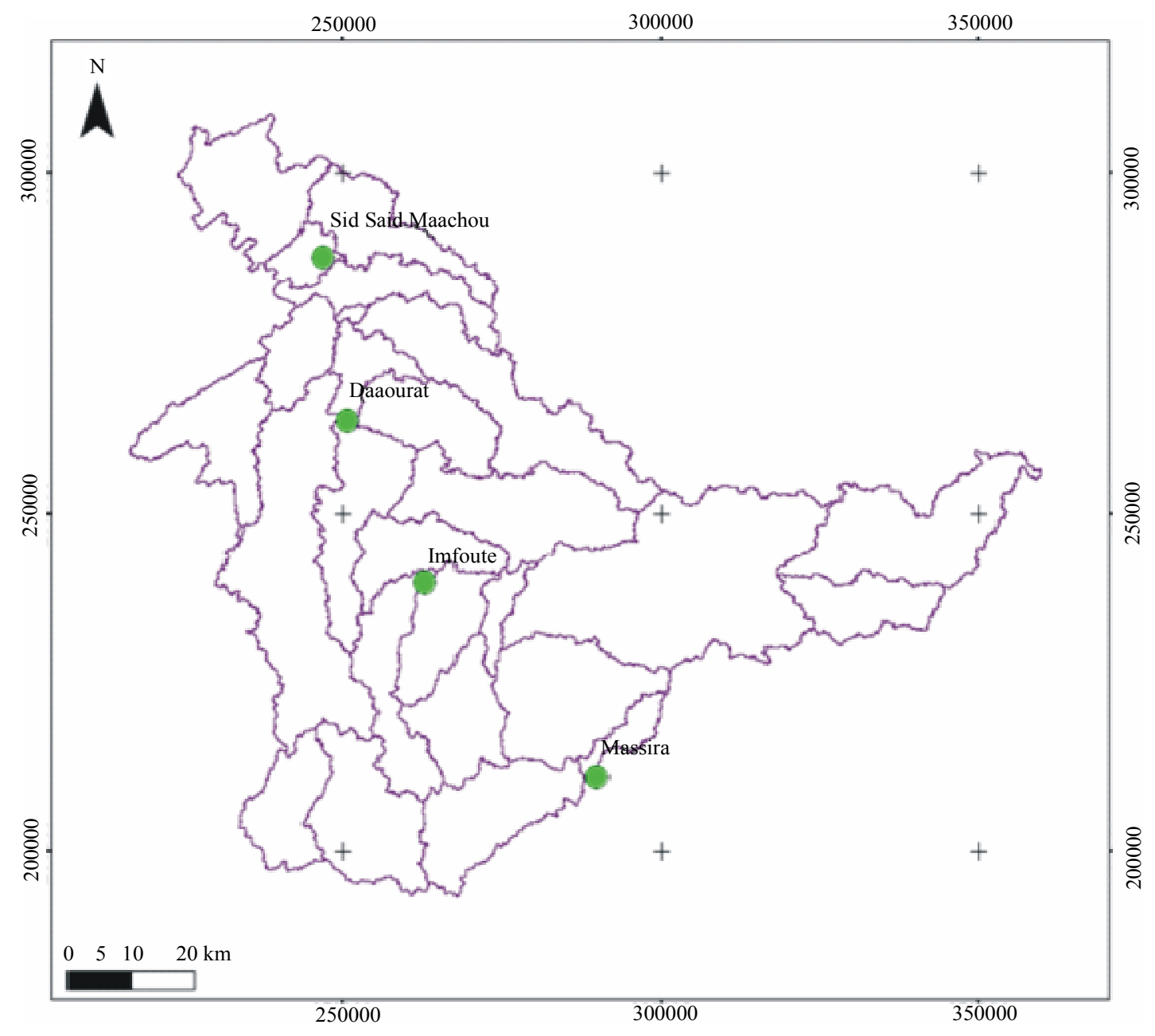

Figure 5. Delineation of sub-basins.

of land use such as urban areas and water surfaces.

Climate data and data from the three dams are subsequently integrated in the appropriate input files of the model.

Once the various input data have been entered, the next step in the process of implementation of the SWAT model is to calibrate and validate the model of the area studied.

The calibration of the model is to find the optimal values of the model parameters which allow better representation of the physical reality of the functioning of the modeled basin [16]. The calibration consists in determining the values which allow the matching of the parameters stimulated by the model and with those observed at a particular point in the basin. The calibration procedure used is the Parasol method [17]. The calibration has been performed at the Imfout dam by comparing monthly water yield of the river at the dam and that simulated by the model. The choice of this reservoir model calibration is dictated by the following considerations:

- Area: the area of the sub-basin associated with this reservoir is the largest compared to the others.

- Representativity of data: this sub-basin is one for which most climate data is available because it is the dam nearest stations measuring precipitation and temperature.

The calibration consisted in inputting into the model on a daily basis data concerning:

- The year 2001 (365 values) to initialize the parameters of the model;

- The years 2002 to 2005 (4 years * 365 values $=1460$ values) for model calibration.

To assess the performance of model calibration, a second phase, called model validation, is implementation. In this phase the values of the model parameters found in the calibration phase are applied to a new period to estimate the difference between the values simulated by the model and those observed in the field [18]. The assessment of this difference is carried out using indicators such as the linear correlation coefficient and the coefficient of Nash. This index provides a more accurate assessment of the efficiency relative to the volumes of the 
flow and absolute deviations [19]. This is defined by the Formula (2):

$$
\text { ENash }=1-\frac{\sum_{i=1}^{N}\left(y_{i o b s}-y_{\text {sim }}\right)}{\sum_{i=1}^{N}\left(y_{\text {iobs }}-\bar{y}_{\text {obs }}\right)}
$$

With:

$y_{\text {iobs }}=$ mean value of the observed variable

$y_{o b s}=$ observed value of the variable

$y_{\text {sim }}=$ simulated value of the variable

The Nash criterion varies from $-\infty$ for very bad adjustment to 1 . A value close to 1 indicates a strong correlation between observations and simulations [20].

Model validation was conducted over a five year period (2006-2010).

\section{Results and Discussion}

\section{Results of Calibration and Validation of the Model}

Calibration of the model is based on a twenty hydrological parameters. Aiming at reducing the number of iterations and the computing time we selected eleven parameters. The choice of this set of parameters was done based on sensitivity analysis results. SWAT implements the Latin Hypercube method to study how the variation in the input parameters can affect the variation of the output. This study reveals that the most sensitive parameters are $\mathrm{CN} 2$, Alpha_BF and soil parameters.

The model requires making twenty thousand iterations to determine the optimum values. This corresponds to duration of treatment of more than 960 hours.

The following table shows the parameters that we have chosen with their meanings and their default values after calibration (Table 1).

It appears from Figures $\mathbf{6}$ and $\mathbf{7}$ that the observed flow and simulated flow are well represented. The Nash coefficient was 0.63 for the calibration period and 0.53 for the validation period of the model. The level of this indicator appears satisfactory on the quantity and spatial distribution of data used [21]. This calibration can be further improved by working on a longer and more spatial series of data.

The balance of water generated by the model shows a dominance of evapotranspiration which represents more than $70 \%$ of incident rainfall while surface runoff generally does not exceed $25 \%$. The following table summarizes the balance of water for each year of the study period from 2002 to 2010 (Table 2).

Table 1. Table of parameters used.

\begin{tabular}{|c|c|c|c|c|}
\hline Parameters & Description & Default & Interval of variation & Optimal value \\
\hline $\mathrm{CN} 2$ & The curve number & - & -25 à 25 & 21.8 \\
\hline ALPHA_BF & coefficient of depletion of groundwater & 0.048 & 0 à 1 & 0.022 \\
\hline CANMX & Index covered up & 0 & 0 à 10 & 4.24 \\
\hline EPCO & $\begin{array}{l}\text { compensation factor evapotranspiration for plant uptake } \\
\text { as a function of depth }\end{array}$ & 1 & 0 à 1 & 0.85 \\
\hline ESCO & compensation factor soil evaporation according to the depth & 0.95 & 0 à 1 & 0.58 \\
\hline REVAPMM (mm) & threshold of evaporation from the water table & 1 & -100 à 100 & 94.56 \\
\hline SLOPE & the slope & - & -25 à 25 & 0.87 \\
\hline SOL_AWC & Amount of water available to plants & $0.16-0.19$ & -25 à 25 & 24.56 \\
\hline SOL_K (mm.h-1) & Saturated hydraulic conductivity & $22.7-24.73$ & -25 à 25 & 2.35 \\
\hline SOL_Z $(\mathrm{mm})$ & Layer depth & - & -25 à 25 & 10.15 \\
\hline SURLAG (jours) & response time of the watershed & 4 & 0 à 10 & 7.45 \\
\hline
\end{tabular}

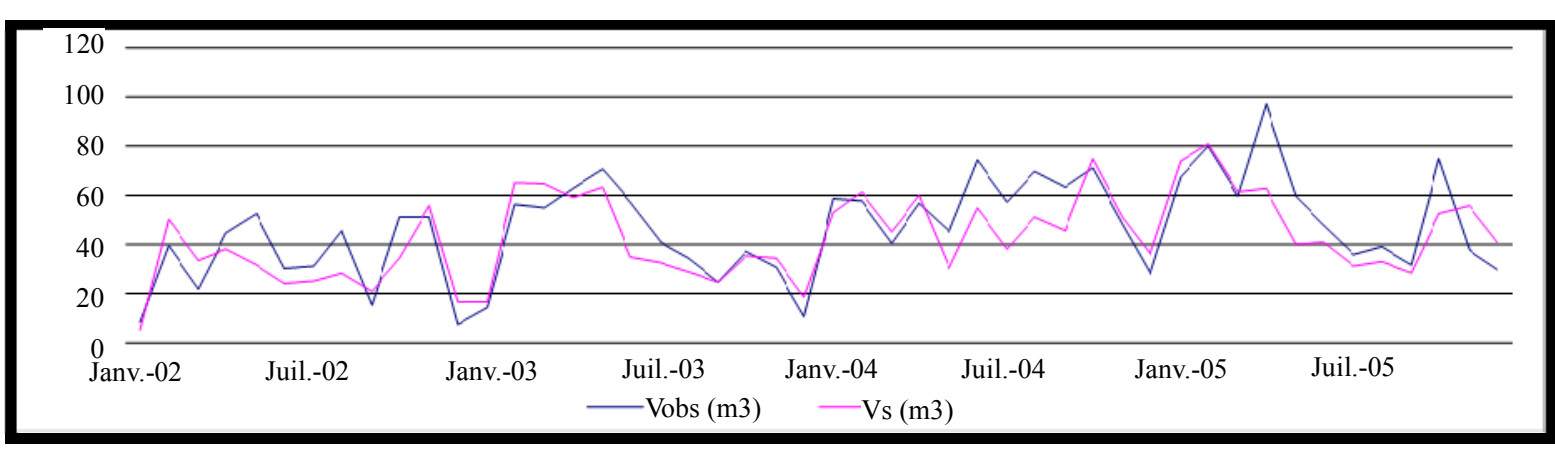

Figure 6. Flow diagram comparing observed and simulated flow for the calibration. 


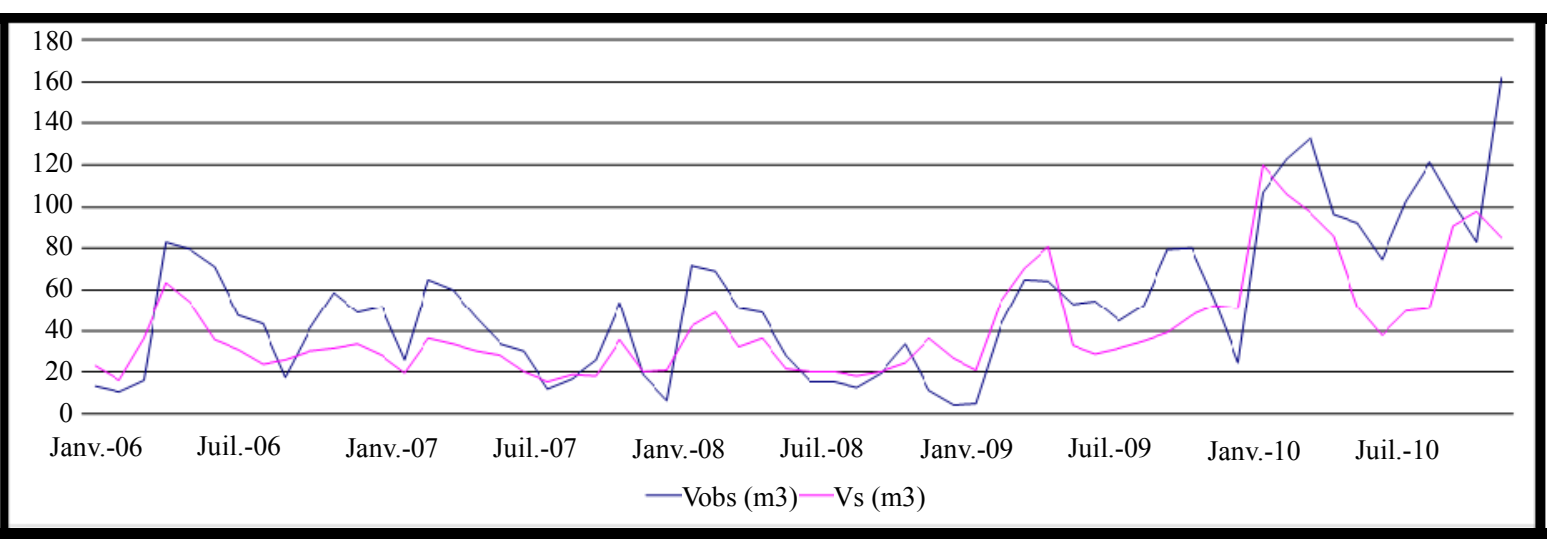

Figure 7. Comparison chart of the observed flow and simulated flow for validation period.

Table 2. Water balance for the period of calibration and validation.

\begin{tabular}{cccc}
\hline & Years & Runoff $(\mathrm{mm})$ & Evapotranspiration $(\mathrm{mm})$ \\
\hline & 2002 & 72.48 & 176.11 \\
Calibration period & 2003 & 86.96 & 191.91 \\
& 2004 & 93.86 & 186.96 \\
& 2005 & 36.73 & 120.57 \\
2006 & 72.4 & 200.83 \\
& 2007 & 51.83 & 108.86 \\
Validation period & 2008 & 106.74 & 144.26 \\
& 2009 & 81.89 & 195.78 \\
& 2010 & 76.38 & 170.36 \\
\hline
\end{tabular}

\section{Conclusions}

In conclusion the first results obtained are satisfactory for both phases: calibration and validation.

The wedging of the model on the studied zone made it possible to determine the optimal values of the various parameters of the SWAT model and to establish the partition of the hydrological balance sheet in the basin of Oum Er Rbiaa. It also made it possible to estimate the importance of different hydrological processes at each sub-basin drained by the three dams. This will provide a better guide for the management methods in these dams, especially as far as the production of electric energy which constitutes currently the main function of these dams is concerned.

Nevertheless, simulations and water balance can be improved by integrating more data, especially climate related data. The calibration of the model also opens new perspectives on the study of the effects of climate change and changes induced by human activities on water resources system in both terms of quantity and quality.

\section{REFERENCES}

[1] H. Bouaouda and Y. Timoulali, "The Contribution of Remote Sensing and GIS Hydrogeological Research in the Sahel Region of Central Doukkala (Western Morocco)," Remote Sensing Francophonie: Critical Analysis and Outlook. Éd. AUF, Hachette Diffusion Internationale, Laussane, 2000, pp. 205-213.

[2] B. Héléne, "Variational Data Assimilation for Distributed Hydrological Modeling of Floods with Fast Kinetics," Ph.D. Dissertation, Institut de National Polytecnique, Toulouse, 2008

[3] A. Chaponnière, G. Boulet, A. Chehbouni and M. Aresmouk, "Understanding Hydrological Processes with Scarce Data in a Mountain Environment," Hydrological Processes, Vol. 22, No. 12, 2008, pp. 1908-1921. doi:10.1002/hyp.6775

[4] J. P. Fortin, R. Moussa, C. Bocquillon and J. P. Villeneuve "Hydrotel, a Distributed Hydrological Model Compatible with Remote Sensing and Geographical Information Systems," Revue des Sciences de l'eau, Vol. 8, No. 1, 1995, pp. 97-124,

[5] R. Srinivasan, T. S. Ramanarayanan, J. G. Arnold, and S. 
T. Bednarz, "Large Area Hydrologic Modeling and Assessment. Part 2: Model Application," Journal of the American Water Resources Association, Vol. 34, No. 1, 1998, pp. 91-101.

[6] L. Boithias, "Transfer Modeling of Pesticides in Watershed Scale during Vintage," Ph.D. Dissertation, Institut Polytechnique de Toulouse, Toulouse, 2012

[7] H. Somaya, "Study on Wetland Vegetation in Morocco Catalog and Analysis of Plant Biodiversity and Identification of Major Plant Groups," Ph.D. Dissertation, University Mohamed V Rabat, Rabat, 2004, p. 104.

[8] H. Somaya, "Study on Wetland Vegetation in Morocco Catalog and Analysis of Plant Biodiversity and Identification of Major Plant Groups," Ph.D. Dissertation, University Mohamed V Rabat, Rabat, 2004, p. 105.

[9] J. G. Arnold, R. Srinivasan, R. S. Muttiah and J. R. Williams, "Large Area Hydrologic Modelling and Assessment. Part I: Model Development," Journal of the American Water Resources Association, Vol. 34, No. 1, 1998, pp. 73-89. doi:10.1111/j.1752-1688.1998.tb05961.x

[10] F. L. Ogden, J. Garbrecht, P. A. DeBarry and L. E. Johnson, "GIS and Distributed Watershed Models, II: Modules, Interfaces, and Models," Journal of Hydraulic Engineering, Vol. 6, No. 6, 2001, pp. 515-523. doi:10.1061/(ASCE)1084-0699(2001)6:6(515)

[11] S. L. Neitsch, J. G. Arnold, J. R. Kiniry, J. R. Williams and K. W. King, "Soil and Water Assessment Tool Theoretical Documentation-Version 2005," Soil and Water Research Laboratory, Agricultural Research Service, US Department of Agriculture, Temple, 2005.

[12] B. B. Ashagre, "SWAT to Identify Watershed Management Options: Anjeni Watershed, Blue Nile Basin, Ethiopia," Master's Thesis, Cornell University, New York, 2009.

[13] G. S. Shimelis, R. Srinivasan and B. Dargahi, "Hydrological Modelling in the Lake Tana Basin, Ethiopia Using SWAT Model," The Open Hydrology Journal, Vol. 2, No. 1, 2008, pp. 49-62. doi:10.2174/1874378100802010049

[14] C. H. Green, M. D. Tomer, M. Di Luzio and J. G. Arnold,
"Hydrologic Evaluation of the Soil and Water Assessment Tool for a Large Tile-Drained Watershed in IWO," American Society of Agricultural and Biological Engineers Vol. 49, No. 2, 2006, pp. 413-422.

[15] A. Sheshukov, K. Douglas-Manking and P. Daggupati, "Evaluating the Effectiveness of Unconfined Livestock BMPs Using SWAT" Proceeding of the International SWAT Conference, Colorado, 7-9 August 2009, pp. 204 211

[16] P. W. Gassman, M. R. Reyes, C. H. Green and J. G. Arnold, "The Soil and Water Assessment Tool: Historical Development, Applications, and Future Research Directions," American Society of Agricultural and Biological Engineers, Vol. 50, No. 4, 2007, pp. 1211-1250.

[17] A. Van Griensven and T. Meixner, "Methods to Quantify and Identify the Sources of Uncertainty for River Basin Water Quality Models," Water Science and Technology, Vol. 53, No. 1, 2006, pp. 51-59. doi:10.2166/wst.2006.007

[18] K. L. White and I. Chaubey, "Sensitivity Analysis, Calibration, and Validations for a Multisite and Multivariable SWAT Model," Journal of the American Water Resources Association, Vol. 41, No. 5, 2005, pp. 1077-1089. doi:10.1111/j.1752-1688.2005.tb03786.x

[19] P. Reungsang, R. S. Kanwar, M. Jha, P. W. Gassman, K. Ahmad and A. Saleh, "Calibration and Validation of SWAT for the Upper Maquoketa River Watershed," Center for Agricultural and Rural Development, Iowa State University, Ames, 2005.

[20] A. Fadil, H. Rhinane, A. Kaoukaya, Y. Kharchaf and O. Bachir, "Hydrologic Modeling of the Bouregreg Watershed (Morocco) Using GIS and SWAT Model," Journal of Geographic Information System, Vol. 3 No. 4, 2011, pp. 279-289. doi:10.4236/jgis.2011.34024

[21] C. Santhi, J. G. Arnold, J. R. Williams, W. A. Dugas and L. Hauck, "Validation of the SWAT Model on a Large River Basin with Point and Nonpoint Sources,"Journal of the American Water Resources Association, Vol. 37, No. 5, 2001, pp. 1169-1188. doi:10.1111/j.1752-1688.2001.tb03630.x 